\title{
Desenvolvimento de chocolate branco com extrato de erva-mate
}

\author{
Development of white chocolate with yerba mate extract
}

\author{
Catia Santin Zanchett ${ }^{1 *}$, Marcelo Luis Mignoni', Najara Pinto Ribeiro Barro', Clarissa Dalla Rosa ${ }^{2}$ \\ 'Universidade Regional Integrada do Alto Uruguai e das Missões (URI), Departamento de Engenharia de Alimentos, Campus Erechim, Erechim/RS - Brasil \\ ${ }^{2}$ Universidade Federal Fronteira Sul (UFFS), Departamento de Engenharia Ambiental, Campus Erechim, Erechim/RS - Brasil

\section{*Corresponding Author} \\ Catia Santin Zanchett, Universidade Regional Integrada do Alto Uruguai e das Missões (URI), Departamento de Engenharia de Alimentos, \\ Campus Erechim, Av. Sete de Setembro, 1621, CEP: 99709-910, Erechim/RS - Brasil, e-mail: catiazanchett@yahoo.com.br
}

Cite as: Development of white chocolate with yerba mate extract. Braz. J. Food Technol., v. 19, e2015073, 2016.

Received: Sept. 25, 2015; Accepted: May 3, 2016

\section{Resumo}

O chocolate é um produto apreciado mundialmente e as tendências do setor apontam para a busca de inovações e a procura por produtos mais saudáveis. Da mesma forma, muitos estudos têm demonstrado os benefícios nutricionais da erva-mate (Ilex paraguariensis), dentre eles a atividade antioxidante atribuída ao seu alto teor de compostos fenólicos, tornando-a uma matéria-prima potencial para o desenvolvimento de novos produtos. O presente trabalho tem por objetivo a aplicação de extrato de erva-mate no desenvolvimento de chocolate branco, a fim de elaborar um produto inovador e que atenda às necessidades de saudabilidade dos consumidores. Foram elaboradas formulações com 1\%, 3\% e 5\% de extrato de erva-mate, determinadas por delineamento composto central $2^{2}$ para o extrato de erva-mate e vanilina. Todas as amostras apresentaram padrão microbiológico em conformidade com o exigido pela legislação brasileira e foram analisadas sensorialmente, a fim de verificar quais eram as mais aceitas pelos consumidores. As formulações com $1 \%$ e $3 \%$ de extrato de erva-mate foram as mais aceitas para todos os atributos analisados. Os teores de compostos fenólicos variaram de

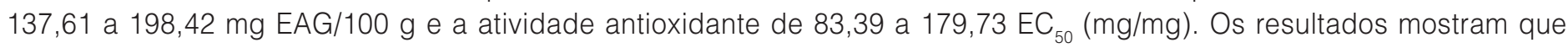
o produto desenvolvido apresentou boa aceitabilidade e a aplicação de extrato de erva-mate acrescentou ao chocolate branco compostos fenólicos com ação antioxidante.

Palavras-chave: Chocolate branco; Erva-mate; Análise sensorial; Polifenóis; Antioxidantes.

\section{Summary}

Chocolate is a globally appreciated product and industry trends point to the search for innovations and demand for healthier products. Similarly, many studies have shown the nutritional benefits of yerba mate (Ilex paraguariensis), including the antioxidant activity attributed to its high content of phenolic compounds, making it a potential raw material for new products development. The aim of this study was the application of yerba mate extract in the white chocolate development for an innovative product that meets the healthiness of consumer needs. Formulations were prepared with $1 \%, 3 \%$ and $5 \%$ of yerba mate extract, determined by central composite design $2^{2}$ for the yerba mate extract and vanillin. All samples showed microbiological standard as required by Brazilian law and were sensory analyzed in order to check which samples were most accepted by consumers. Formulations with $1 \%$ and $3 \%$ of yerba mate extract were the most accepted for all attributes. Phenolic compounds levels varied from 137.61 to $198.42 \mathrm{mg} / 100 \mathrm{~g} \mathrm{EAG}$ and the antioxidant activity varied from 83.39 to 179.73 EC50 $(\mathrm{mg} / \mathrm{mg})$. Results showed that the developed product had a good sensory acceptability and that the yerba mate extract added phenolic compounds with antioxidant action to the white chocolate.

Keywords: White chocolate; Yerba mate; Sensory analysis; Polyphenols; Antioxidants. 


\section{Introdução}

A legislação brasileira define chocolate branco como "[...] o produto obtido a partir da mistura de manteiga de cacau com outros ingredientes, contendo, no mínimo, 20\% (g/100 g) de sólidos totais de manteiga de cacau. O produto pode apresentar recheio, cobertura, formato e consistência variados [...]" (BRASIL, 2005b).

O crescimento do setor de chocolates no Brasil tem sido constante nos últimos anos, o país é o terceiro maior fabricante de chocolates do mundo, atrás dos Estados Unidos e Alemanha (DOCE REVISTA, 2014). No ano de 2014, a produção brasileira foi de 781 mil toneladas (ABICAB, 2015a).

Ocupando o $3^{\circ}$ lugar no ranking mundial de consumidores, o brasileiro tem aumentado gradativamente o consumo de chocolate nos últimos três anos, gerando um aquecimento cada vez maior do mercado. Dados de 2015 mostram que 2,8 kg de chocolates são consumidos por pessoa ao ano no Brasil. Em 2010, essa média era de $1,65 \mathrm{~kg}$. Percebe-se, portanto, um aumento de 69,6\% no consumo de chocolate de 2010 a 2015 (ABICAB, 2013, 2015b).

Vários efeitos benéficos à saúde têm sido atribuídos ao consumo de erva-mate. Pesquisas revelam grande capacidade antioxidante do extrato de erva-mate (BERTÉ et al., 2011; PRECl et al., 2011). Estudos com extrato de erva-mate demonstram a eficácia na ação cardioprotetora (MENINI et al., 2007). O consumo regular de chá mate melhora as defesas antioxidantes por múltiplos mecanismos, tanto pelo aumento da circulação de compostos bioativos, como pela regulação dos mecanismos celulares e enzimáticos que combatem o estresse oxidativo (MATSUMOTO et al., 2009). As substâncias contidas na erva-mate apresentam ações antioxidantes, estimulantes, antimicrobianas e diuréticas (BERTÉ et al., 2011).

O Estado do Rio Grande do Sul destaca-se no setor ervateiro com expressiva importância socioeconômica e cultural. No Estado, são cultivados mais de 30 mil hectares de erva-mate e sua produção anual é de mais de 260 mil toneladas, cerca de 51,5\% da produção nacional. O desenvolvimento tecnológico de novos produtos e processos bem como a expansão do mercado consumidor são de relevante importância para diversificação do público alvo e ampliação da distribuição geográfica de produtos com erva-mate (SINDIMATE'RS, 2015).

Dentro desse contexto, o objetivo do presente trabalho foi desenvolver um conceito diferenciado de chocolate branco adicionado de extrato de erva-mate, um ingrediente regional de muita tradição no Estado do Rio Grande do Sul e oferecer ao consumidor um produto inovador que atenda suas necessidades de saudabilidade, tendo em vista que a erva-mate é rica em antioxidantes e o chocolate branco, por não conter liquor de cacau em sua fórmula, não traz benefícios à saúde como os chocolates que contêm elevado teor de massa de cacau.

\section{Material e métodos}

\subsection{Material}

O extrato de erva-mate (Matebrás) foi utilizado em sua forma verde. Para elaboração dos chocolates, foram utilizados manteiga de cacau (Cargill), leite em pó integral e desnatado (Consutati), açúcar (Copersucar), polirricinoleato de poliglicerol - PGPR (Palsgaard), lecitina de soja (Olfar) e vanilina (Rodhia).

\subsection{Métodos}

\subsubsection{Caracterização físico-química do extrato de erva-mate}

As determinações da umidade e dos compostos fenólicos totais do extrato de erva-mate foram realizadas segundo métodos descritos em literatura clássica (ZENEBON; PASCUET, 2005; SINGLETON; ROSSI JUNIOR, 1965, respectivamente).

\subsubsection{Elaboração dos chocolates}

A partir de uma formulação base (42\% de açúcar, $33,5 \%$ de manteiga de cacau, 6\% leite em pó integral, $18 \%$ de leite em pó desnatado, 0,4\% de lecitina de soja, $0,1 \%$ de PGPR) foram elaborados sete experimentos de chocolate branco com extrato de erva-mate, variando em sua composição a concentração de extrato de erva-mate e vanilina. A mistura dos ingredientes foi realizada em misturador (Netzsch ChocoEasy) com capacidade para $35 \mathrm{~kg}$. Foi inicialmente adicionada no equipamento parte da manteiga de cacau (25\%) e, após o derretimento desta, os ingredientes em pó foram adicionados (açúcar e leite). Nesse mesmo equipamento, foi realizada a conchagem seca por $3 \mathrm{~h}$ a $60^{\circ} \mathrm{C}$. Posteriormente foi realizada a conchagem úmida por $1 \mathrm{~h}$ a $60^{\circ} \mathrm{C}$, sendo então adicionado o restante de manteiga de cacau, juntamente com o PGPR e a lecitina de soja. Depois da conchagem, as amostras foram refinadas, em um único estágio, em moinho de esferas (Netzsch) com rotação de 54 rpm e temperatura constante de $40^{\circ} \mathrm{C}$, até atingir a granulometria de 25 micra, determinada através de micrômetro digital (Mitutoyo), sendo que para leitura o produto foi misturado a óleo mineral, com cinco repetições para verificação da repetibilidade. O extrato de erva-mate e a vanilina foram adicionados na etapa de refino, para esta etapa não sofrer efeito da temperatura, a fim de manter o conteúdo de polifenóis inalterados. As amostras refinadas foram temperadas manualmente em bancada de mármore, sendo inicialmente derretidas em micro-ondas em potência $70 \%$, até que o chocolate atingisse a temperatura de 40 a $42{ }^{\circ} \mathrm{C}$. O chocolate foi colocado em bancada de mármore e foi movimentado com uma espátula, até que a temperatura ficasse entre 
23 a $25^{\circ} \mathrm{C}$. Depois dessa etapa, o chocolate foi reaquecido até a temperatura de $27-28^{\circ} \mathrm{C}$. As amostras temperadas foram moldadas em formas de acetato e resfriadas em geladeira convencional, por 20 minutos. Retiradas da geladeira, as amostras foram desmoldadas e embaladas individualmente em papel alumínio, em sala climatizada a $20-23^{\circ} \mathrm{C}$. As barras de chocolate foram armazenadas a $20^{\circ} \mathrm{C}$ por sete dias, permitindo a formação dos cristais $\beta$, que conferem estabilidade ao chocolate diante de oscilações de temperatura.

\subsubsection{Delineamento experimental}

Os experimentos foram realizados a partir de um delineamento composto central, nele as concentrações de extrato de erva-mate $\left(X_{1}\right)$ e de vanilina $\left(X_{2}\right)$ foram estabelecidas como variáveis independentes, estudadas em três níveis. Foram realizados sete experimentos com três repetições no ponto central. Os níveis de variações e as variáveis independentes estão apresentados na Tabela 1.

Como respostas a este planejamento experimental, foram analisados os atributos em relação aos parâmetros sensoriais (sabor, aparência e impressão global) e intenção de compra, apresentadas no item 3.3.1.

\subsubsection{Análises microbiológicas}

Para as sete formulações estudadas, foram pesquisados os micro-organismos recomendados na RDC $n^{\circ} 12$ (BRASIL, 2001), Coliformes a $45^{\circ} \mathrm{C}$, Salmonella s.p. e Staphylococcus coagulase positiva, de acordo com a metodologia descrita no Manual de Métodos de Análise Microbiológica de Alimentos (SILVA et al., 2007).

\subsubsection{Análise sensorial}

A aceitação das amostras de chocolate foi avaliada por 50 provadores não treinados, quanto aos atributos de sabor, aparência e impressão global, através do teste afetivo de aceitabilidade baseado em escala hedônica estruturada de cinco pontos ( 5 = gostei muito, 3 = não gostei nem desgostei e 1=desgostei muito). Além disso, os consumidores indicaram a intenção de compra do produto por meio de escala de cinco pontos ( $5=$ certamente compraria, 3=talvez compraria, talvez não compraria e $1=$ certamente não compraria). Esta pesquisa foi aprovada pelo comitê de ética em pesquisa da URI - Campus Erechim sob o número de parecer 371.478 em 30/08/2013.

Amostras de $10 \mathrm{~g}$ foram distribuídas aos provadores de forma monádica sequencial, segundo um delineamento de blocos completos balanceados, sendo apresentadas com códigos de três números aleatórios. Todos os julgadores provaram as sete amostras. Entre uma amostra e outra, foram utilizadas água mineral à temperatura ambiente e bolacha água e sal para eliminar o gosto residual das amostras.

\subsubsection{Caracterização dos chocolates e determinação de compostos fenólicos totais e atividade antioxidante}

A umidade foi determinada segundo métodos descritos nas Normas Analíticas do Instituto Adolfo Lutz (ZENEBON; PASCUET, 2005).

A análise de textura instrumental foi conduzida em máquina universal de ensaios mecânicos (WDW - 100B Time Group) e um probe foi movido perpendicularmente em velocidade predeterminada (102 mm/min) sobre a barra de chocolate, para determinação da força (N) necessária para quebrá-las.

A viscosidade plástica de Casson foi determinada em viscosímetro programável (Brookfield) com spindle (S27).

A determinação dos compostos fenólicos totais dos chocolates foi realizada com base nos métodos descritos por Efraim et al. (2006) e Hammerstone et al. (1999). A primeira etapa das análises consistiu no desengorduramento das amostras. Foram pesados $2 \mathrm{~g}$ de amostra e adicionados $10 \mathrm{~mL}$ de hexano. As amostras permaneceram no ultrassom por 2 minutos e, em seguida, foram centrifugadas e o sobrenadante, descartado. Esse procedimento foi repetido por duas vezes. O hexano restante foi evaporado utilizando fluxo contínuo de $\mathrm{N}_{2}$. Em seguida, foram extraídos os compostos fenólicos. No resíduo desengordurado, foram adicionados $10 \mathrm{~mL}$ de uma solução de acetona:água:ácido acético (70:29,5:0,5). A amostra foi homogeneizada, o sobrenadante foi separado por centrifugação e recolhido em um balão volumétrico de $50 \mathrm{~mL}$. O procedimento foi repetido por duas vezes. O volume foi completado para $50 \mathrm{~mL}$ com solução extratora. O extrato resultante foi utilizado para as determinações de compostos fenólicos totais espectrofotometricamente, de acordo com o método de Folin-Ciocalteau, descrito por Singleton e Rossi Junior (1965), modificado por Kim et al. (2003). A absorbância da cor foi avaliada a $725 \mathrm{~nm}$, em espectrofotômetro UV-Vis (marca Hitachi, modelo U-2000) e foi construída curva de calibração utilizando ácido gálico.

Para análise da atividade antioxidante dos chocolates, foi utilizado o teste de DPPH ${ }^{*}$, baseado na redução do radical orgânico DPPH (1-difenil-2-picril-hidrazina),

Tabela 1. Variáveis independentes e níveis de planejamento (valores reais e codificados).

\begin{tabular}{lcccc}
\multicolumn{1}{c}{ Variáveis independentes (\%) } & Variáveis codificadas & $\mathbf{- 1}$ & $\mathbf{0}$ & $\mathbf{+ 1}$ \\
Concentrações de extrato de erva-mate & $X_{1}$ & 1 & 3 & 5 \\
Concentrações de vanilina & $X_{2}$ & 0,02 & 0,04 & 0,06 \\
\hline
\end{tabular}


que apresenta o máximo de absorção a 515-520 nm. O método utilizado foi descrito por Brand-Williams et al. (1995), o chocolate reagiu com o radical estável DPPH em uma solução de etanol. Na forma de radical, o DPPH possui uma absorção característica a $517 \mathrm{~nm}$, a qual desaparece após a redução pelo hidrogênio removido de um composto antioxidante. A redução do radical do DPPH foi medida através da leitura da absorbância a 517 nm em espectrofotômetro UV-Vis (Hitachi, modelo U-2000).

\subsubsection{Análises estatísticas}

Os resultados do teste de aceitação sensorial foram submetidos à análise estatística, utilizando-se o software Statistica versão 8.0 (Statsoft). A análise de variância (ANOVA) foi usada para detectar a diferença significativa entre as amostras (ao nível de \%). Os valores médios foram comparados entre si pelo teste de Tukey a 5\% de probabilidade de erro $(p \leq 0,05)$.

\section{Resultados e discussão}

\subsection{Caracterização físico-química do extrato de erva-mate}

Os resultados para a determinação de umidade e compostos fenólicos totais do extrato de erva-mate estão apresentados na Tabela 2.

De acordo com o Ministério da Saúde, produtos solúveis como chá e café devem apresentar no máximo 5,0\% de umidade (BRASIL, 2005a). O extrato de erva-mate apresentou um teor médio de umidade de 5,63\%, ligeiramente acima do exigido pela legislação para produtos solúveis.

Tabela 2. Valores médios e desvio padrão das análises físico-químicas para o extrato de erva-mate.

\begin{tabular}{ll}
\multicolumn{1}{c}{ Análise } & Média \pm SD \\
Umidade e voláteis g/100g & $5,63 \pm 0,01$ \\
Compostos fenólicos totais g EAG/100g & $4,43 \pm 0,14$ \\
\hline
\end{tabular}

\subsection{Análises microbiológicas}

$\mathrm{Na}$ Tabela 3, encontram-se os resultados das análises microbiológicas realizadas para as amostras de chocolate branco com adição de extrato de erva-mate.

Conforme pode ser observado, todos os micro-organismos apresentaram valores inferiores ao recomendado pela legislação, o que garante a segurança microbiológica para o consumo desses chocolates. A sanidade microbiológica das amostras comprova também o correto método no seu preparo e as Boas Práticas de Fabricação vinculadas ao processo.

\subsection{Testes sensoriais}

\subsection{Aceitabilidade}

A matriz do delineamento composto central $2^{2} \mathrm{em}$ relação aos parâmetros sensoriais (sabor, aparência e impressão global) das formulações de chocolate branco com adição de extrato de erva-mate, com os resultados médios das notas atribuídas pelos julgadores a cada parâmetro avaliado, pode ser visualizada na Tabela 4.

Conforme pode ser observado, não houve diferença significativa (ao nível de 5\%) para o atributo sabor entre as amostras $\mathrm{F} 1$ e $\mathrm{F} 3$ (ambas com 5\% de erva-mate), F2 e F4 (com 1\% de erva-mate), F5, F6 e F7 (repetições com $3 \%$ de erva-mate). Tal resultado indica que as diferentes concentrações de vanilina empregadas nas formulações dos chocolates não interferiram no sabor do produto final de forma perceptível. O aumento na concentração de extrato de erva-mate resultou na menor aceitação do produto, conforme observado nas notas atribuídas para as amostras F1 e F3. As amostras que apresentaram maiores médias para o atributo sabor foram F2 e F4 com 1\% de erva-mate. Algumas observações feitas nas fichas de avaliação sensorial ressaltaram que o sabor mais suave de erva-mate agradou mais ao paladar.

No atributo aparência, foi verificado que não houve diferenciação estatística significativa entre as médias das

Tabela 3. Resultados das análises microbiológicas para as amostras de chocolate.

\begin{tabular}{cccc} 
Amostras & Coliformes a $\mathbf{4 5}^{\circ} \mathbf{N P M / g}$ & $\begin{array}{c}\text { Staphylococcus coagulase } \\
\text { positiva UFC/g }\end{array}$ & Salmonella sp./25 $\mathbf{g}$ \\
F 1 & $<3$ & Ausente & Ausente \\
F 2 & $<3$ & Ausente & Ausente \\
F 3 & $<3$ & Ausente & Ausente \\
F 4 & $<3$ & Ausente & Ausente \\
F 5 & $<3$ & Ausente & Ausente \\
F 6 & $<3$ & Ausente & Ausente \\
F 7 & $<3$ & Ausente & Ausente \\
Padrão microbiológico & 10 & $5,0 \times 10^{-2}$ & Ausência 25g \\
(BRASIL, 2001) & & & \\
\hline F
\end{tabular}

F1 $=5 \%$ de extrato de erva-mate e $0,06 \%$ de vanilina; F2 = 1\% de extrato de erva-mate e 0,06\% de vanilina; F3 = 5\% de extrato de erva-mate e $0,02 \%$ de vanilina; F4 = 1\% de extrato de erva-mate e 0,02\% de vanilina; F5 = F6 =F7 = 3\% de extrato de erva-mate e 0,04\% de vanilina 
formulações F1 e F3; F2 e F4; F5, F6 e F7 (repetições). Nesta análise, observa-se que as formulações F1 e F3 foram as que apresentaram os menores valores de médias das notas atribuídas pelos provadores, sendo esses valores considerados estatisticamente iguais entre si. Essas formulações apresentaram cor verde bastante acentuada, o que provavelmente foi responsável por sua menor aceitação entre as demais formulações em relação à aparência. Destaca-se que alguns julgadores descreveram algumas percepções na ficha de avaliação sensorial em relação à aparência, como: "a cor é muito escura" ou "cor não agrada". Segundo Dutcoski (2013), o impacto visual é um elemento que a indústria alimentícia utiliza para tornar um alimento apetitoso, sendo que os sinais visuais são muito importantes no controle de qualidade da matéria-prima, no julgamento de um alimento para um determinado atributo. As características visuais do alimento induzem o consumidor a esperar certo sabor correspondente, isso porque, cada vez que se deparar com determinada imagem, recordar-se-á de tudo o que já aprendeu sobre aquele alimento em particular. $\mathrm{O}$ fato de os consumidores não estarem acostumados com uma aparência verde do chocolate, possivelmente influenciou de forma negativa a avaliação da aparência do produto.

Similarmente ao que foi observado em relação ao sabor, no atributo impressão global, as amostras F2 e F4, produzidas a partir dos ensaios com menor concentração de extrato de erva-mate (1\%), tiveram melhores resultados, não diferindo estatisticamente entre si. As formulações F5, F6 e F7 não apresentaram diferença significativa entre si. As amostras com a concentração maior de extrato de erva-mate (5\%), F1 e F3, tiveram as menores médias e não houve diferença significativa entre essas amostras.

O resultado do teste de intenção de compra concorda com o resultado do teste de aceitação, sendo que as formulações F2 e F4 receberam as maiores notas pelos provadores, comprovando melhor aceitação. Foi observado que as formulações F1 e F3 apresentaram as menores médias, refletindo menor aceitação pelos provadores.

Para avaliar se a influência das variáveis é significativa $(p<0,05)$ para as formulações de chocolate, foram obtidos gráficos de Pareto (Figura 1) com os efeitos estimados (valor absoluto) no delineamento composto central $2^{2}$ para os parâmetros sensoriais (sabor, aparência e impressão global) das formulações de chocolate branco com adição de extrato de erva-mate.

Analisando a Figura 1, observa-se que a variável extrato de erva-mate influenciou negativamente todos os atributos sensoriais analisados, ou seja, quanto maior a concentração adicionada menor a aceitabilidade do produto. A concentração de vanilina adicionada nas formulações não apresenta efeito significativo no intervalo de $95 \%$ de confiança para a aceitação das amostras. Tais dados confirmam os resultados obtidos na Análise de Variância (ANOVA).

Verifica-se que a interação das variáveis independentes, extrato de erva-mate e vanilina, não apresentou efeito significativo (ao nível de 5\%) sobre a aceitação dos produtos para os atributos avaliados.

A partir dos resultados obtidos nos testes de aceitação e intenção de compra, conclui-se que as formulações F2 e F4; F5, F6 e F7 (repetições) foram consideradas como as formulações preferidas. Entre as amostras F2 e F4, ambas com $1 \%$ de erva-mate, optou-se por prosseguir com as análises de compostos fenólicos totais e atividade antioxidante a partir da amostra F4, uma vez que para todos os testes essa amostra obteve médias superiores à amostra F2, mesmo não havendo diferença significativa em nível de 5\% para ambas as amostras. Assim, as amostras F4 e F5 foram escolhidas para prosseguir com as análises de caracterização físico-química e quantificação de polifenóis e atividade antioxidante.

Tabela 4. Matriz do delineamento composto central $2^{2}$ (valores reais e codificados) e valores médios das respostas \pm desvio padrão (DP) dos parâmetros.

\begin{tabular}{|c|c|c|c|c|c|c|}
\hline \multirow[b]{2}{*}{ Amostras } & \multicolumn{2}{|c|}{ Variáveis Independentes } & \multicolumn{4}{|c|}{ Valores Médios \pm DP } \\
\hline & $X_{1}$ & $X_{2}$ & Sabor & Aparência & $\begin{array}{l}\text { Impressão } \\
\text { global }\end{array}$ & $\begin{array}{l}\text { Intenção de } \\
\text { compra }\end{array}$ \\
\hline F 1 & $5(+1)$ & $0,06(+1)$ & $3,26 \pm 1,08^{d e}$ & $3,22 \pm 1,00^{\circ}$ & $3,30 \pm 0,97^{\circ}$ & $3,10 \pm 1,19^{b, c}$ \\
\hline F 2 & $1(-1)$ & $0,06(+1)$ & $4,18 \pm 0,70^{a b}$ & $3,96 \pm 0,92^{a}$ & $3,94 \pm 0,63^{a}$ & $3,88 \pm 0,88^{a}$ \\
\hline F 3 & $5(+1)$ & $0,02(-1)$ & $2,88 \pm 1,17^{e}$ & $3,06 \pm 1,08^{c d}$ & $2,98 \pm 1,08^{c d}$ & $2,70 \pm 1,20^{\circ}$ \\
\hline F 4 & $1(-1)$ & $0,02(-1)$ & $4,34 \pm 0,59^{a}$ & $4,06 \pm 0,79^{a}$ & $4,14 \pm 0,61^{a}$ & $4,10 \pm 0,74^{a}$ \\
\hline F 5 & $3(0)$ & $0,04(0)$ & $3,62 \pm 0,77^{c d}$ & $3,34 \pm 0,94^{b c d}$ & $3,52 \pm 0,73^{b c}$ & $3,32 \pm 1,11^{b}$ \\
\hline F 6 & $3(0)$ & $0,04(0)$ & $3,74 \pm 0,90^{b c}$ & $3,48 \pm 0,93^{b c}$ & $3,54 \pm 0,86^{b c}$ & $3,34 \pm 1,15^{b}$ \\
\hline F 7 & $3(0)$ & $0,04(0)$ & $3,74 \pm 0,88^{b c}$ & $3,50 \pm 0,93^{b c}$ & $3,72 \pm 0,73^{b c}$ & $3,40 \pm 0,98^{b}$ \\
\hline & MDS & & 0,45 & 0,38 & 0,39 & 0,45 \\
\hline
\end{tabular}

$X_{1}=$ concentração de extrato de erva-mate (\%); e $X_{2}=$ concentração de vanilina (\%); M.D.S: diferença mínima significativa; Médias seguidas de letras iguais na mesma coluna indicam não haver diferença significativa ao nível de 5\% de probabilidade de erro (Teste de Tukey). 
Desenvolvimento de chocolate branco com extrato de erva-mate

Zanchett, C. S. et al.

\subsection{Caracterização dos chocolates}

$\mathrm{Na}$ Tabela 5 estão apresentados os valores obtidos na caracterização dos chocolates das amostras de chocolate adicionadas de $1 \%$ e $3 \%$ de extrato de erva-mate, formulações F4 e F5, respectivamente.

Os valores encontrados para o teor de umidade nas amostras de chocolate estão semelhantes a outros trabalhos descritos na literatura (GENOVESE; LANNES, 2009). A diferença nos teores de umidade entre as amostras pode ter sido influenciada diretamente pelos diferentes valores de umidade relativa do ar no ambiente de processamento e ao longo dos dias em que os chocolates foram produzidos (LUCCAS, 2001).

Os resultados obtidos para a dureza mostraram variabilidade na força de quebra em função da quantidade adicionada de extrato de erva-mate. Os chocolates apresentaram viscosidade plástica de Casson $\left(\eta_{c a}\right)$ variando entre 3460,63 a 8641,12 cP. Estes valores estão de acordo com o recomendado na literatura (SAMPAIO, 2011), em que a viscosidade plástica de Casson para os chocolates deve apresentar valores entre 1 e 20 Pa.s, ou seja, 1000 a 20000 cP. Todas as amostras diferiram significativamente entre si, sendo que a amostra F5, com maior concentração de extrato de erva-mate (3\%), apresentou maior valor de viscosidade plástica. Analisando os valores obtidos para as amostras, observa-se que a viscosidade aumenta conforme o aumento da quantidade de extrato na formulação.

Observa-se que a amostra F5, com maior quantidade de extrato de erva-mate, apresentou maior teor de compostos fenólicos. O resultado foi semelhante aos valores descritos por Souza (2010), que estudou a estabilidade oxidativa de diferentes marcas de chocolate amargo com $70 \%$ de cacau e encontrou valores entre 153 e 215 mg EAG/100 g. Para essa mesma amostra, o resultado obtido foi superior
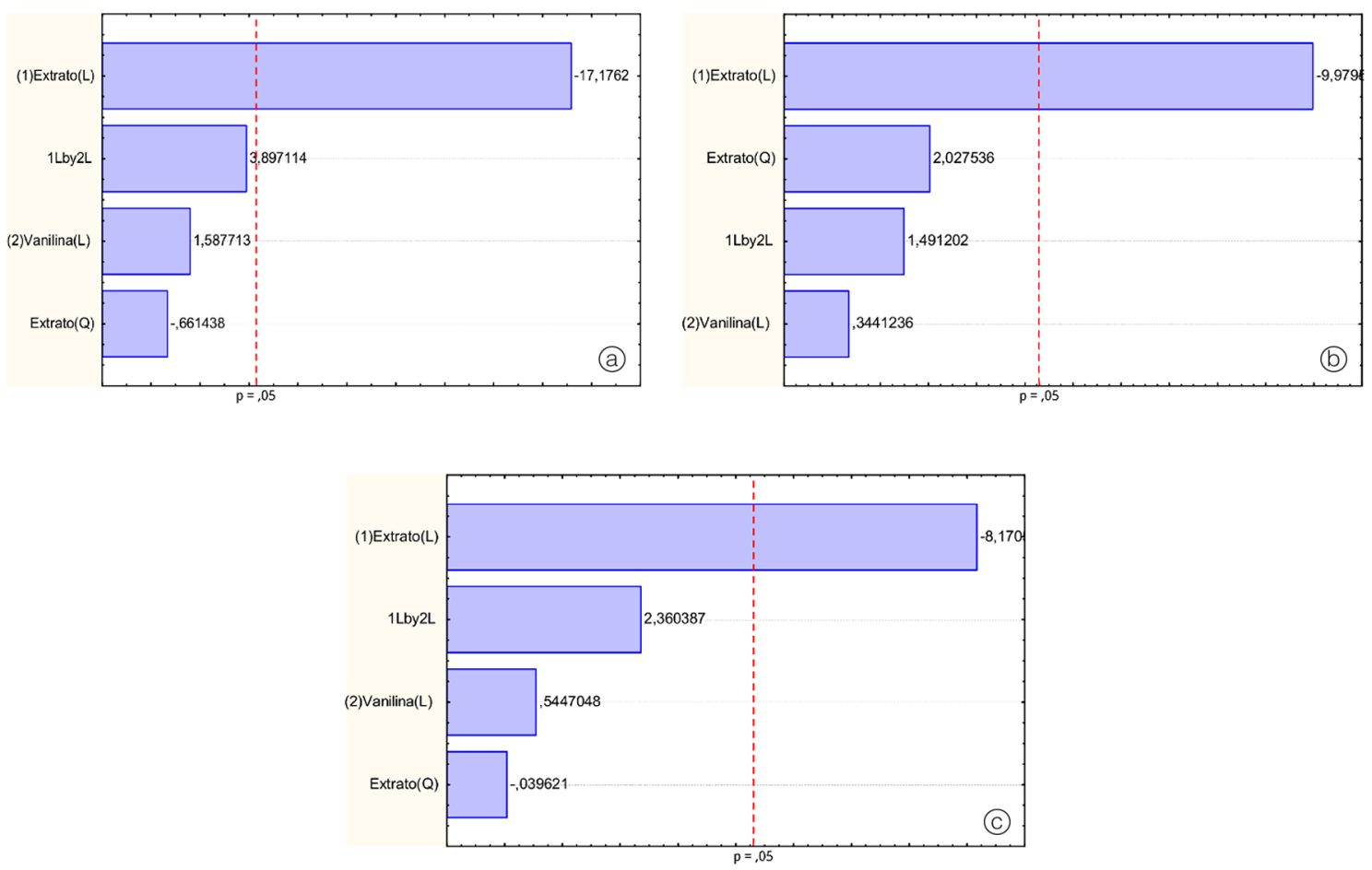

Figura 1. Gráfico de Pareto para análise de chocolates brancos com adição de extrato de erva-mate e vanilina. (a) - Sabor; (b) - Aparência; (c) - Impressão global.

Tabela 5. Características físico-químicas.

\section{Parâmetros}

Umidade $(\mathrm{g} / 100 \mathrm{~g})$

Força de quebra (N)

Viscosidade $-\eta_{\mathrm{ca}}(\mathrm{CP})$

Compostos fenólicos totais (mg EAG/100g)

Atividade antioxidante $\mathrm{EC}_{50}(\mathrm{mg} / \mathrm{mg})$
F4

\section{F 5}

$\begin{aligned} 1,39 & \pm 0,01^{\mathrm{a}} \\ 587,04 & \pm 1,61^{\mathrm{b}} \\ 8338,91 & \pm 2,56^{\mathrm{b}} \\ 137,61 & \pm 1,65^{\mathrm{b}} \\ 198,42 & \pm 13,34^{\mathrm{a}}\end{aligned}$

$1,14 \pm 0,07^{b}$

$726,51 \pm 1,75^{\mathrm{a}}$

$8641,12 \pm 1,37^{a}$

$179,73 \pm 9,15^{2}$

$83,39 \pm 5,36^{b}$

Médias \pm desvio padrão seguidas de letras iguais na mesma coluna indicam não haver diferença significativa ao nível de 5\% (Teste de Tukey); $F 4=1 \%$ de extrato de erva-mate e $0,02 \%$ de vanilina; $F 5=3 \%$ de extrato de erva-mate e $0,04 \%$ de vanilina 
ao relatado por Steinberg et al. (2003) para chocolates amargos (170 mg EAG/100 g). Salvador (2011), ao estudar a atividade antioxidante de diferentes marcas comerciais de chocolate, encontrou valores semelhantes para chocolate ao leite (entre 141 e $205 \mathrm{mg}$ EAG/100 g) e valores superiores para o chocolate meio amargo (de 809 a $831 \mathrm{mg}$ EAG/100 g). A variação entre os dados encontrados na literatura pode ter origem na fermentação das sementes de cacau, uma vez que essa etapa é responsável pelas maiores perdas de compostos fenólicos, considerando o processamento do cacau desde o fruto. A composição da massa de cacau dos chocolates também pode influenciar o conteúdo de compostos fenólicos totais (SAMPAIO, 2011). Considerando que uma dieta rica em polifenóis deve atingir $1 \mathrm{~g} / \mathrm{dia}$ (ARABBI et al., 2004), a ingestão de uma barra de $100 \mathrm{~g}$ de chocolate branco adicionado de $3 \%$ de extrato de erva-mate (F4) pode contribuir com até $19,8 \%$ desse total.

Os valores da atividade antioxidante dos compostos fenólicos presentes nas amostras de chocolates são apresentados em EC ${ }_{50}(\mathrm{mg} / \mathrm{mg})$ e demonstram a quantidade de amostra necessária para inibir em $50 \%$ a atividade de $1 \mathrm{mg}$ do radical livre DPPH, assim, quanto menor o valor de $\mathrm{EC}_{50}$, melhor é a capacidade antioxidante da amostra. O valor da atividade antioxidante do chocolate branco adicionado de $3 \%$ de extrato de erva-mate $\left(83,39 \mathrm{EC}_{50}\right)$ é aproximadamente 2,15 vezes maior do que a determinada no chocolate branco adicionado de $1 \%$ de extrato de erva-mate $\left(179,73 \mathrm{EC}_{50}\right)$. Os dados confirmam que a incorporação de erva-mate no chocolate branco aumenta a atividade antioxidante do produto. No caso dos chocolates analisados, quanto maior o teor de compostos fenólicos, maior a atividade antioxidante. Os valores obtidos foram semelhantes aos encontrados por Souza (2010), que analisou a atividade antioxidante de três marcas comerciais de chocolate amargo e encontrou valores de $\mathrm{EC}_{50}$ entre 20,59 e 101 ( $\left.\mathrm{mg} / \mathrm{mL}\right)$. Salvador (2011), ao estudar a capacidade antioxidante em chocolates, não detectou atividade antioxidante em chocolate branco. Segundo Shahidi et al. (1992), os compostos fenólicos atuam como antioxidantes sequestradores de radicais livres e quelantes de metais, apresentando ação tanto na etapa de iniciação quanto na propagação do processo oxidativo. Desta forma, os compostos fenólicos impedem a oxidação de vários ingredientes do alimento, o que justifica seu uso em alimentos com alto teor de lipídios.

\section{Conclusão}

O extrato de erva-mate pode ser utilizado no desenvolvimento de novos produtos, pois revelou um elevado teor de compostos fenólicos. A adição de extrato de erva-mate no chocolate branco acrescentou ao produto compostos fenólicos com atividade antioxidante. A quantidade de polifenóis da amostra F5 (3\% de extrato de erva-mate) mostrou-se similar a alguns chocolates ao leite e meio amargo vendidos comercialmente.
Neste sentido, este trabalho indicou a possibilidade de acrescentar ao chocolate branco compostos antioxidantes presentes no extrato de erva-mate, oferecendo aos consumidores um produto inovador, que atende a suas necessidades de saudabilidade, apresentando um conceito diferenciado de chocolate.

\section{Referências}

ARABBI, P. R.; GENOVESE, M. I.; LAJOLO, F. M. Flavonoids in vegetables food s cammonly consumed in Brazil and estimates ingestion by the Brazilian population. Journal of Agricultural and Food Chemistry, Easton, v. 52, n. 5, p. 1124-1131, 2004. http://dx.doi.org/10.1021/jf0499525. PMid:14995109.

ASSOCIAÇÃO BRASILEIRA DA INDÚSTRIA DE CHOCOLATE, CACAU, AMENDOIM, BALAS E DERIVADOS - ABICAB. Páscoa 2013 chega recheada com mais de 100 lançamentos. São Paulo, 2013. Disponível em: <http://www.abicab.org.br/pascoa2013-chega-recheada-com-mais-de-100-lancamentos/>. Acesso em: 10 maio 2015.

ASSOCIAÇÃO BRASILEIRA DA INDÚSTRIA DE CHOCOLATE, CACAU, AMENDOIM, BALAS E DERIVADOS - ABICAB. Pesquisas e estatísticas. São Paulo, 2015a. Disponível em: <http://www. abicab.org.br/estatisticas/>. Acesso em: 10 maio 2015.

ASSOCIAÇÃO BRASILEIRA DA INDÚSTRIA DE CHOCOLATE, CACAU, AMENDOIM, BALAS E DERIVADOS - ABICAB. Setor de chocolate registra queda na produção. São Paulo, 2015b. Disponivel em: <http://www.abicab.org.br/setor-de-chocolateregistra-queda-na-producao/>. Acesso em: 10 maio 2015.

BERTÉ, K. A. S.; BEUX, M. R.; SPADA, P. K. W. D. S.; SALVADOR, M.; HOFFMANN-RIBANI, R. Chemical composition and antioxidant activity of yerba-mate (Ilex paraguariensis A.St.-Hil., Aqui foliaceae) extract as obtained by spray drying. Journal of Agricultural and Food Chemistry, Easton v. 59, n. 10, p. 5523-5527, 2011. http://dx.doi.org/10.1021/jf2008343. PMid:21510640.

BRAND-WILLIAMS, W.; CUVELIER, M. E.; BERSET, C. Use of a free radical method to evaluate antioxidant activity. Lebensmittel Wissenschaft und Technologie, London, v. 28, n. 1, p. 25-30, 1995. http://dx.doi.org/10.1016/S0023-6438(95)80008-5.

BRASIL. Ministério da Saúde. Agência Nacional de Vigilânica Sanitária. Resolução RDC n 12, de 02 de janeiro de 2001. Aprova o Regulamento Técnico sobre padrões microbiológicos para alimentos. Diário Oficial [da] República Federativa do Brasil, Brasília, DF, 10 jan. 2001

BRASIL. Ministério da Saúde. Agência Nacional de Vigilância Sanitária. Resolução RDC n² 277, de 22 de setembro de 2005. Aprova o Regulamento técnico para café, cevada, chá, erva-mate e produtos solúveis. Diário Oficial [da] República Federativa do Brasil, Brasília, DF, 23 set. 2005a.

BRASIL. Ministério da Saúde. Agência Nacional de Vigilânica Sanitária. Resolução RDC n² 264, de 22 de setembro de 2005. Aprova o Regulamento Técnico para chocolate e produtos de 
Desenvolvimento de chocolate branco com extrato de erva-mate

Zanchett, C. S. et al.

cacau. Diário Oficial [da] República Federativa do Brasil, Brasília, DF, 23 set. 2005b.

DOCE REVISTA, São Paulo, v. 27, n. 242, dez. 2014. 32 p. Anuário.

DUTCOSKI, S. D. Análise sensorial de alimentos. 4. ed. Curitiba: PUCPRESS, 2013. $521 \mathrm{p}$.

EFRAIM, P.; TUCCI, M. L.; PEZOA-GARCÍA, N. H.; HADDAD, R.; EBERLIN, M. N. Teores de compostos fenólicos de sementes de cacaueiro de diferentes genótipos. Brazilian Journal of Food Technology, Campinas, v. 9, n. 4, p. 229-236, 2006.

GENOVESE, M. I.; LANNES, S. C. S. Comparison of total phenolic content and antiradical capacity of powders and "chocolates" from cocoa and cupuaçu. Ciência e Tecnologia de Alimentos, Campinas, v. 29, n. 4, p. 810-814, 2009. http://dx.doi.org/10.1590/ S0101-20612009000400017.

HAMMERSTONE, J. F.; LAZARUS, S. A.; MITCHELL, A. E.; RUCKER, R.; SCHMITZ, H. H. Identification of procyanidins in cocoa (Theobroma cacao) and chocolate using high-performance liquid chormatography/mass spectrometry. Journal of Agricultural and Food Chemistry, Easton, v. 47, n. 2, p. 490-496, 1999. http://dx.doi.org/10.1021/jf980760h. PMid:10563922.

KIM, D. O.; JEONG, S. W.; LEE, C. Y. Antioxidant capacity of phenolic phytochemicals from various cultivars of plums. Food Chemistry, London, v. 81, n. 3, p. 321-326, 2003. http://dx.doi. org/10.1016/S0308-8146(02)00423-5.

LUCCAS, V. Fracionamento térmico e obtenção de gorduras de cupuaçu alternativas a manteiga de cacau para uso na fabricação de chocolate. 2001. 195 f. Tese (Doutorado em Engenharia Química)-Universidade Estadual de Campinas, Campinas, 2001.

MATSUMOTO, R. L. T.; BASTOS, D. H. M.; MENDONÇA, S.; NUNES, V. S.; BARTCHEWSKY, W.; RIBEIRO, M. L.; DE OLIVEIRA CARVALHO, P. Effects of mate tea (llex paraguariensis) ingestion on RNA expression of antioxidant enzymes, lipid peroxidation, and total antioxidants status in healthy young women. Journal of Agricultural and Food Chemistry, Easton, v. 57, n. 5, p. 17751780, 2009. http://dx.doi.org/10.1021/jf803096g. PMid:19219987.

MENINI, T.; HECK, C.; SCHULZE, J.; DE MEJIA, E.; GUGLIUCCI, A. Protective action of Ilex paraguariensis extract against free radical inactivation of paraoxonase- 1 in high-density lipoprotein. Planta Medica, Stuttgart, v. 73, n. 11, p. 1141-1147, 2007. http:// dx.doi.org/10.1055/s-2007-981585. PMid:17823869.

PRECI, D.; CHICOSKI, A. J.; VALDUGA, A. T.; OLIVEIRA, D.; VALDUGA, E.; TREICHEL, H.; TONIAZZO, G.; CANSIAN, R. L.
Desenvolvimento de iogurte light com extrato de erva-mate (Ilex paraguariensis ST. HIL) e adição de probioticos. Alimentos e Nutrição, Marília, v. 22, p. 27-38, 2011.

SALVADOR, I. Antioxidante e teor de resveratrol em cacau chocolates achocolatados em pó e bebidas lácteas achocolatadas. 2011. 90 f. Dissertação (Mestrado em Ciências)Centro de Energia Nuclear na Agricultura, Universidade de São Paulo, Piracicaba, 2011.

SAMPAIO, C. S. Chocolate meio amargo produzido de amêndoas de cacau fermentadas com polpa de cajá cupuaçu ou graviola: características físico-químicas reológicas e sensoriais. 2011. 80 f. Dissertação (Mestrado em Ciência e Tecnologia de Alimentos)-Universidade Federal de Viçosa, Viçosa, 2011.

SHAHIDI, F.; JANITHA, P. K.; WANASUNDARA, P. D. Phenolic antioxidants. CRC Critical Reviews in Food Science and Nutrition, v. 32, n. 1, p. 67-103, 1992. http://dx.doi. org/10.1080/10408399209527581. PMid:1290586.

SILVA, N.; JUNQUEIRA, V. C. A.; SILVEIRA, N. F. A.; TANIWAKI, M. H.; SANTOS, R. F. S.; GOMES, R. A. R.; OKAZAKI, M. M. Manual de métodos de análise microbiológica de alimentos. 3. ed. São Paulo: Livraria Varela, 2007. 536 p.

SINDICATO DA INDÚSTRIA DO MATE NO ESTADO DO RIO GRANDE DO SUL - SINDIMATE'RS. Dados estatísticos - erva mate. Porto Alegre, 2015. Disponível em: <http://sindimaters. com. br/pagina. php?cont=estatisticas . php\&sel=9>. Acesso em: 01 maio 2015.

SINGLETON, V. L.; ROSSI JUNIOR, J. A. Colorimetry of total phenolics with phosphomolybdic-phosphotungstic acid reagents. American Journal of Enology and Viticulture, Davis, v. 16, p. 144-158, 1965.

SOUZA, A. S. Avaliação de estabilidade térmica e oxidativa de chocolates amargos. 2010. 109 f. Dissertação (Mestrado em Ciência e Tecnologia de Alimentos)-Universidade Federal da Paraíba, João Pessoa, 2010.

STEINBERG, F. M.; BEARDEN, N. M.; KEEN, C. L. Cocoa and chocolate flavonoids: Implications for cardiovascular health. Journal of the American Dietetic Association, Chicago, v. 103, n. 2, p. 215-223, 2003. http://dx.doi.org/10.1053/jada.2003.50028. PMid:12589329.

ZENEBON, O.; PASCUET, N. S. (Coord.). Métodos físico-químicos para análise de alimentos. 4. ed. Brasília, DF: Ministério da Saúde/ANVISA, São Paulo, SP: Instituto Adolfo Lutz, 2005. 1018 p. 